\title{
Disseminação de conhecimento em Educação Especial no Brasil: as CONTRIBUIÇÕes da ABPEE ${ }^{1}$ Dissemination of knowledge in Special Education in Brazil: CONTRIBUtions of the Brazilian Association of Researchers in Special Education
}

\author{
Eduardo José MANZINI² \\ Priscila Moreira CORRÊA ${ }^{3}$ \\ Michele Oliveira da SILVA ${ }^{4}$
}

RESUM O : este artigo apresenta e discute o desenvolvimento da Revista Brasileira de Educação Especial e sua relação com a Associação Brasileira de Pesquisadores em Educação Especial. O contexto de fundação da Associação e da Revista esteve relacionado ao crescimento dos Programas de Pós-graduação - mestrado e doutorado - em Educação e Psicologia. Pouco a pouco, os artigos enviados para a revista aumentaram a participação de autores de diferentes Estados do Brasil. Os dados demonstram que, desde a criação, a Associação e a Revista estiveram conectados, o que reflete no elo entre autores e membros da ABPEE. A partir de 2005, a Revista passou a receber artigos internacionais e expandiu sua participação no cenário nacional e internacional. Conclui-se que a Revista trouxe inestimável contribuição para a área de Educação Especial no Brasil.

PALAVRAS-CHAVE: educação especial; Revista Brasileira de Educação Especial.

A BSTRACT: this article presents and discusses the development of the Brazilian Journal of Special Education and its relation to the Brazilian Association of Researchers in Special Education - ABPEE. The context for the foundation of the Association and the Journal was related to the development of Brazilian graduate level courses (Masters and Doctorate) in education and psychology. Gradually, the articles that were sent in from various Brazilian states increased the number of authors from various parts of the country. The data shows that from the beginning, the Association and the Journal have been connected, revealing a relationship between authors and members of the ABPEE. In 2005, the Journal started receiving international papers, broadening the journal's participation from a national to an international sphere. We conclude that the Journal has become a highly regarded contribution in the field of Special Education in Brazil.

KEYWORDS: Special Education; Brazilian Journal of Special Education.

\footnotetext{
${ }^{1}$ Texto referente à abertura do III Congresso Brasileiro de Educação Especial, em 02 de dezembro de 2008.

2 Docente do Programa de Pós-graduação em Educação e do Depto de Educação Especial da Unesp, Marília. manzini@marilia.unesp.br

${ }^{3}$ Mestranda do Programa de Pós-graduação em Educação da Unesp, Marília. priped@bol.com.br

${ }^{4}$ Mestranda do Programa de Pós-graduação em Educação da Unesp, Marília. miilly1@hotmail.com
} 


\section{INTRODUÇÃo}

A importância da criação de canais para a divulgação do conhecimento em Educação Especial foi exaustivamente discutida pela comuni dade científica nos encontros vol tad os para a disseminação do saber neste campo específico. Está discussão faz parte da história da Educação Especial e foi real izada em vários eventos como no VI Ciclo de Estudos sobre Deficiência M ental, ocorrido na Universidade Federal de São Carlos em 1990; II Seminário Brasileiro de Pesquisa em Educação Especial, na Universidade Estadual do Rio de Janeiro em 1991; no Grupo de Trabalho da ANPEPP, ocorrido em Águas de São Pedro em 1990 e Rio de Janeiro em 1991 e no Grupo de Trabal ho em Educação Especial da ANPED, em São Paulo, 1991, e, em Caxambu, 1991 (DIAS, 2003).

A conclusão consensual ocorrida nesses encontros foi a indicação da necessidade de criar um veículo de integração entre os profissionais que trabalhavam em educação especial, que foi materializado na Revista Brasileira de Educação - RBEE.

Para manter a revista, foi criada a Associação Brasileira de Pesquisadores em Educação Especial ABPEE. Portanto, a ABPEE e a RBEE surgiram como um elo inseparável nesse processo histórico.

No sentido deenfocar as contribuições da ABPEE para a disseminação de conhecimento em Educação Especial no Brasil serão mapeados eapresentados alguns dados sobre as condições de criação da ABPEE e da Revista Brasileira de Educação Especial.

Cabelembrar quea Revista Brasileira de Educação Especial foi lançada em 1992 ea A BPEE criada em 1993, justamente para manter a revista. No editorial da Revista de 1992 é possível encontrar o seguinte relato:

[...] é preciso registrar que este primeiro número se integra aos esforços para a constituição de uma entidade representativa do trabalho científico desenvolvido na área. N este sentido, bom seria que o segundo número desta revista já tivesse a chancela desta entidade, que bem poderia se chamar Associação Brasileira de Pesquisadores em Educação Especial (ABPESP).

Em 13 de agosto de 1993, durante o Seminário Nacional de Educação Especial na UERJ, Rio de Janeiro, concretiza-se a criação da ABPEE. Tornam-se sócios fundadores da ABPEE os seguintes profissionais:

Ana Cristina Barros da Cunha

Ana Helena Moustaché

Elcie Macini

Elsa Midori Shimasaki

Enicéia Gonçalves Mendes

Fátima Elizabeth Denari 
Francisco de Paula Nunes Sobrinho

Júlio Romero Ferreira

Leila Regina D' Oliveira P. Nunes

Liliana H. Weller

Maria Amélia Almeida

Maria Cecília F. Cardoso

Maria da Piedade Resende da Costa

Maria de Lourdes Canziani

Rosana Glat

Sérgio Carvalho

Soraia Napoleão Freitas

Sylvia R. Panico

Tárcia Regina da Silveira Dias

Valdelúcia Alves da Costa

Em 1994, é possível encontrar esse registro no Editorial da Revista Brasileira de Educação Especial:

[...] Os apoios institucionais e da comunidade acadêmica indicam a perspectiva de consolidação do projeto da revista, que se fortalece com o processo de criação da Associação de Pesquisadores em Educação Especial [...]

Em 1995, encontra-se outra menção, no editorial da Revista, que se refere aos objetivos da ABPEE:

[...] Essa consolidação coincide com o nascimento da A ssociação Brasileira de Pesquisadores em Educação Especial (ABPEE),cujas proposta incluem:

Promover e apoiar o aperfeiçoamento técnico científico dos profissionais em Educação Especial e áreas afins;

Estimular a criação de atividades de pós-graduação;

Promover encontros científicos, incentivando a participação dos seus associados em diferentes eventos;

Dar suporte a publicações científicas na área. (A CONSOLIDAÇÃO DE UM PROJETO, Revista Brasileira de Educação Especial, 1995).

Para refletir sobre as contribuições da ABPEE, seria interessante resgatar os objetivos de criação e verificar se eles foram atendidos e al cançados.

Um dos objetivos da ABPEE foi o de estimular a criação de atividades de pós-graduação. Como estava, então, a pós-graduação em Educação no Brasil? 
Realizando um levantamento nos documentos da Capes (2008), foi possível mapear a quantidade de Programas de Pós-graduação.

Nota-se na Figura 1 que, em 1965, iniciam-se os Programas de Mestrado em Educação. Em 1992, quando a Revista foi criada, já existiam 38 cursos de Mestrado em Educação em funcionando.

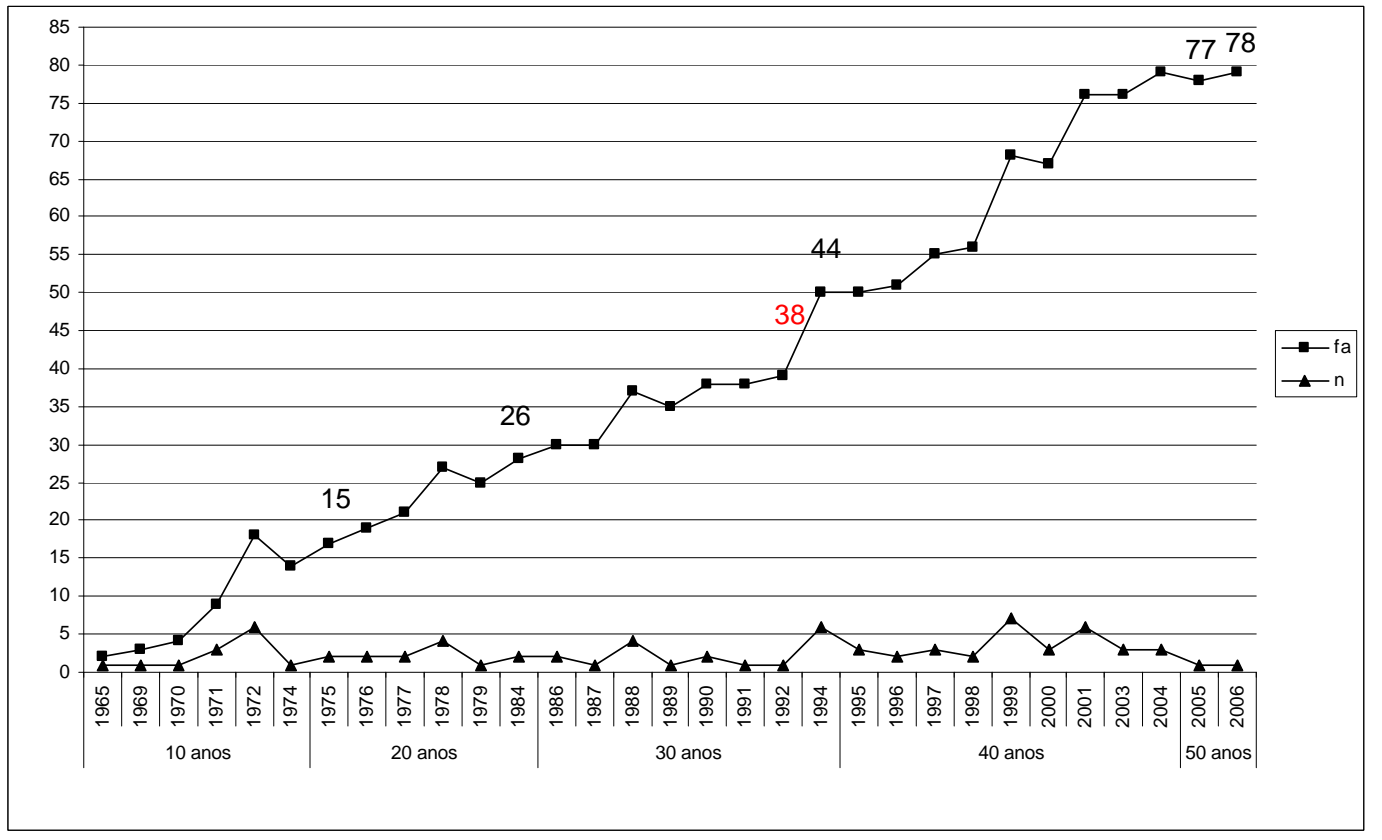

Figura 1 - Quantidade de Cursos de Mestrados em Educação (1995-2006).

Na Figura 2, é possível verificar que existiam 13 Cursos de Doutorado em Educação em 1992.

Conclui-se que esses Programas, até então, não possuíam uma revista específica para apresentar os resultados sobre Educação Especial. Ou seja, frente ao objetivo de "criar um veículo de integração entre os profissionais que trabalhavam em educação especial".

Outra informação interessante que pode ser observada na Figura 2 é a que a Revista foi criada após quase trinta anos de desenvolvimento da Pósgraduação no Brasil, portanto, deveria haver uma demanda reprimida de publicações sobre Educação Especial que poderia ser canalizada para a Revista. 


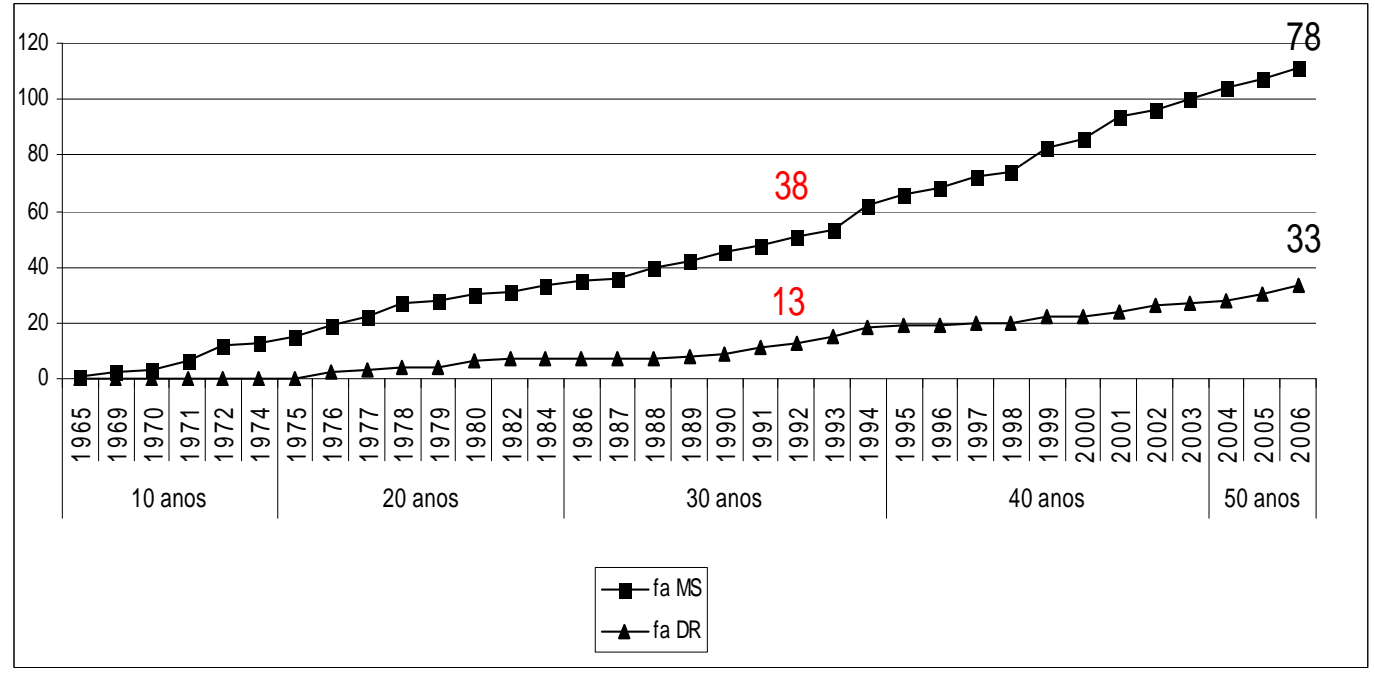

Figura 2 - Quantidade de Cursos de M estrado e Doutorado em Educação (19952006).

Historicamente, sabe-se, também, que vários eram os profissionais da área de psi cologia quetrabal havam em Educação Especial. N essesentido, também foi realizado um levantamento da evolução e quantidade desses Programas de Pós-graduação, apresentado na Figura 3.

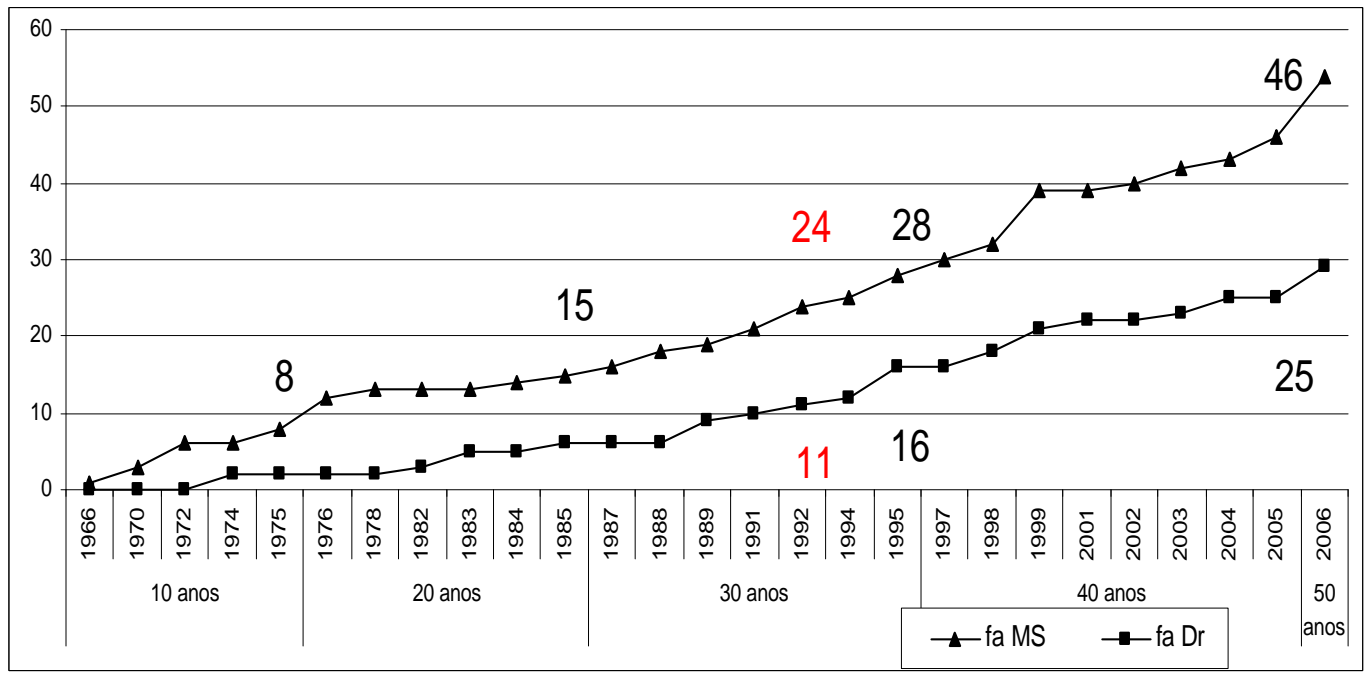

Figura 3 - Quantidade de Cursos de Mestrado e Doutorado em Psicologia (19662006). 
Observando a Figura 3, percebe-se que a Pós-graduação em Psicologia iniciara-se um ano depois (em 1966) dos Programas de Pós-graduação em Educação. Em 1992, quando a Revista Brasileira de Educação Especial foi criada, existiam 24 cursos de Mestrado e 11 de doutorado.

Portanto, a Revista também poderia ser importante veículo de disseminação de conhecimento para os profissionais da Psicologia.

Um outro objetivo da ABPEE foi o de divulgar e disseminar conhecimento (na forma escrita ena forma deeventos). Como, então, esse objetivo pode ser analisado em termos de contribuições para a Educação Especial no Brasil ? Para responder a isso, foi realizada uma análise sobre: 1) Procedência dos autores que publicaram na RBEE e 2) Procedência dos sócios da ABPEE.

Esses dois itens propostos podem indicar a abrangência nacional da revista e da ABPEE e sua contribuição para a educação especial.

As Figuras que seguem apresentam os dados que demonstram o Estado deorigem dos autores queenviaram artigos para a RBEE -Revista Brasileira de Educação Especial.

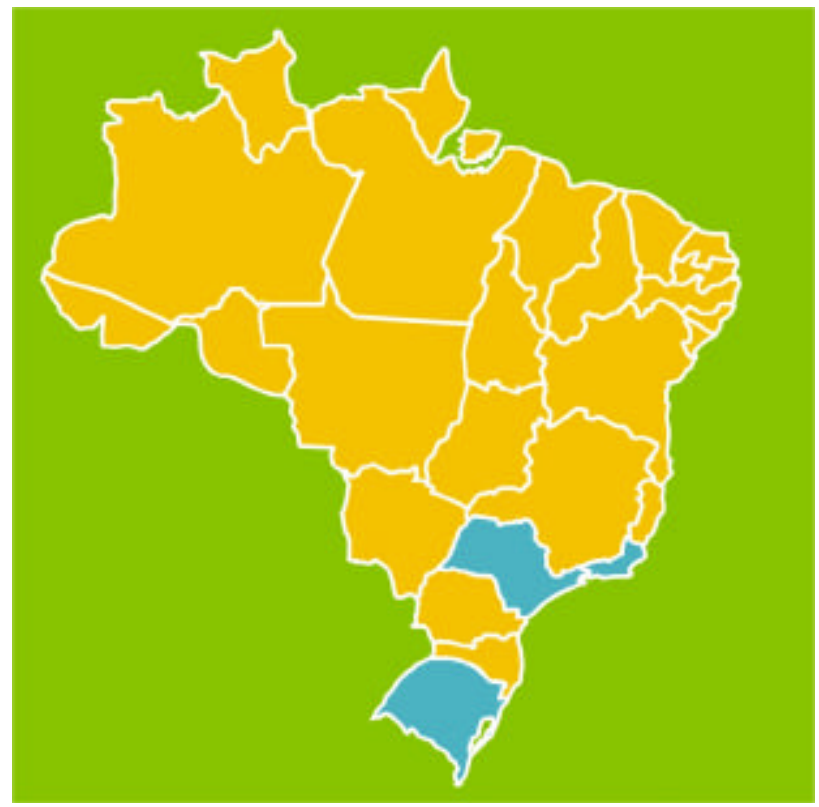

Figura 4 - Estados de origem dos autores que enviaram artigos para a RBEE (1992).

A Figura 4 indica que a primeira Revista Brasileira de Educação Especial obteveartigos provenientes detrês Estados: Rio de Janeiro (2); Rio Grande do Sul (1) eSão Paulo (9). Com certeza, esses artigos foram induzidos pel os sócios fundadores. 
Logo no primeiro número, percebe-se o predomínio de artigos provenientes de São Paulo.

As próximas Figuras apresentam a Frequência acumulada do número de artigos e dos Estados que eles eram oriundos.

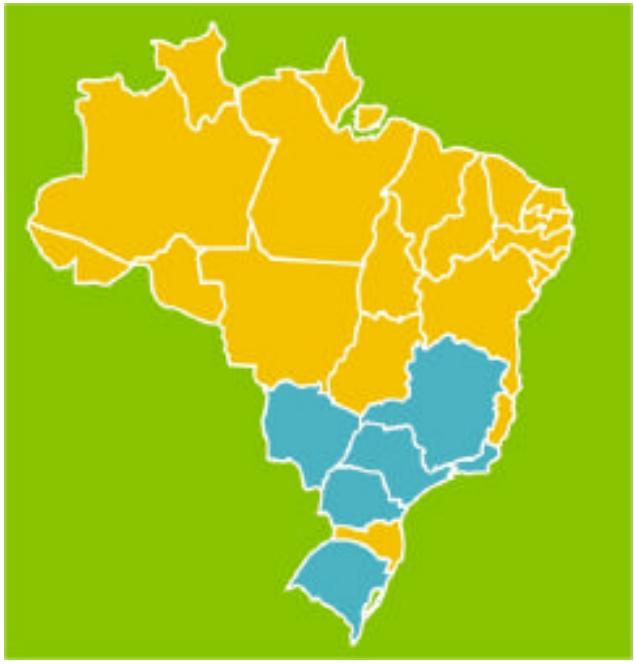

- Mato Grosso do Sul - 1

- Minas gerais - 1

- Paraná - 2

- Rio de Janeiro - 4

- Rio Grande do Sul - 2

- São Paulo - 16

Figura 5 - Estados de origem dos autores que enviaram artigos para a RBEE (1994).

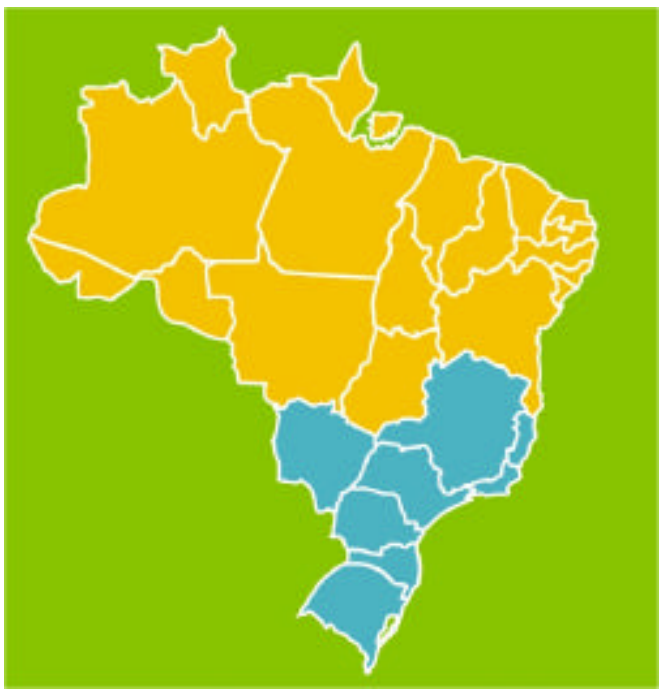

- Espírito Santo - 1

- Mato Grosso do Sul -1

- Minas Gerais - 2

- Paraná - 2

- Rio de Janeiro - 5

- Rio Grande do Sul - 3

- Santa Catarina - 2

- São Paulo - 27

Figura 6 - Estados de origem dos autores que enviaram artigos para a RBEE (1995). 


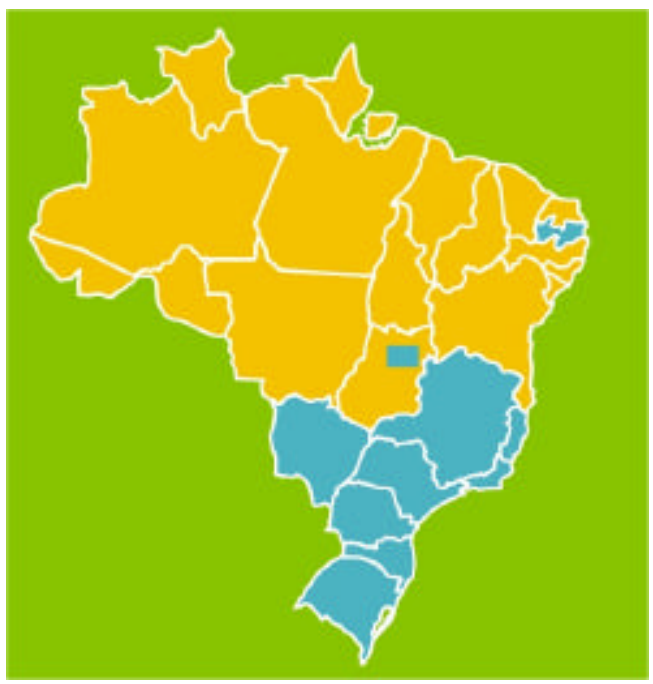
- Brasília - 1
- Espírito Santo - 1
- Mato Grosso do Sul - 2
- Minas Gerais - 2
- Paraíba - 1
- Paraná -2
- Rio de Janeiro - 9
- Rio Grande do Sul - 4
- Santa Catarina - 2
- São Paulo - 30

Figura 7 - Estados de origem dos autores que enviaram artigos para a RBEE (1996).

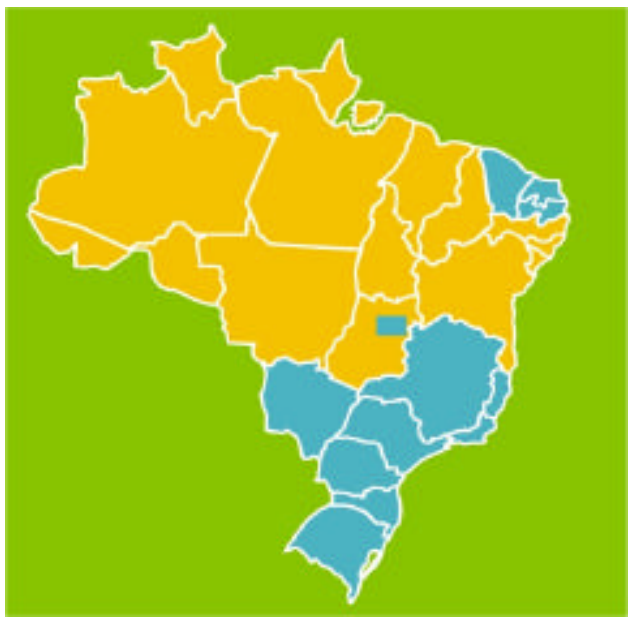
- Brasília - 1
- Ceará - 1
- Espírito Santo - 2
- Mato Grosso do Sul - 3
- Minas Gerais - 3
- Paraíba - 1
- Paraná-3
- Rio de Janeiro - 11
- Rio Grande do Norte - 1
- Rio Grande do Sul - 5
- Santa Catarina - 2
- São Paulo - 33

Figura 8 - Estados de origem dos autores que enviaram artigos para a RBEE (1999). 


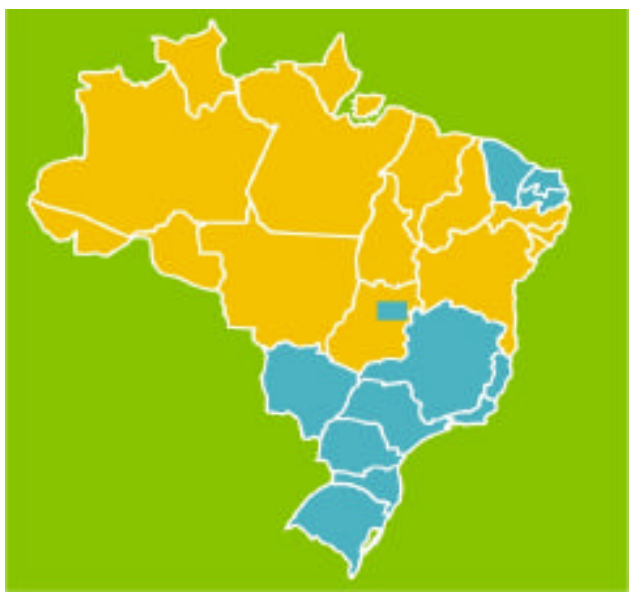

$\begin{array}{ll}\text { - } & \text { Brasília - } 2 \\ \text { - } & \text { Ceará }-1 \\ \text { - } & \text { Espírito Santo }-2 \\ \text { - } & \text { Mato Grosso do Sul }-3 \\ \text { - } & \text { Pinas Gerais }-3 \\ \text { - } & \text { Paraíba }-1 \\ \text { - } & \text { Rio de Janeiro }-12 \\ \text { - } & \text { Rio Grande do Norte }-1 \\ \text { - } & \text { Rio Grande do Sul }-5 \\ \text { - } & \text { Santa Catarina }-2 \\ \text { - } & \text { São Paulo - } 38\end{array}$

Figura 10- Estados de origem dos autores que enviaram artigos para a RBEE (2000).

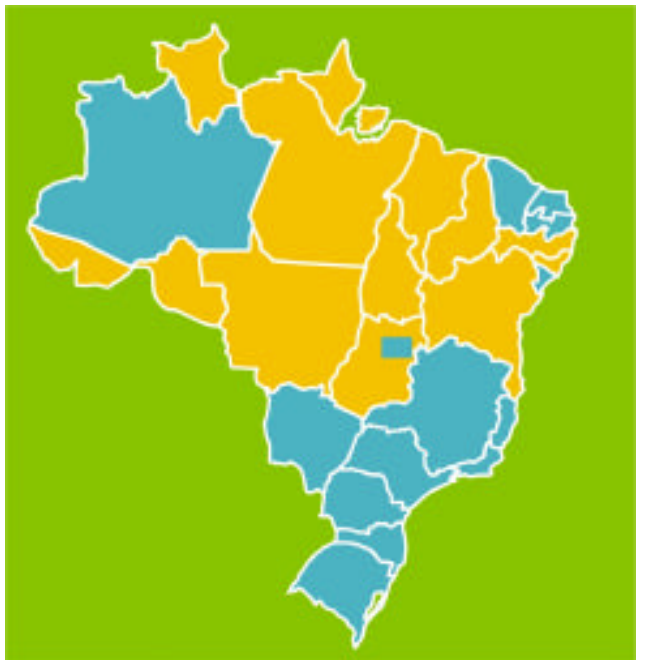

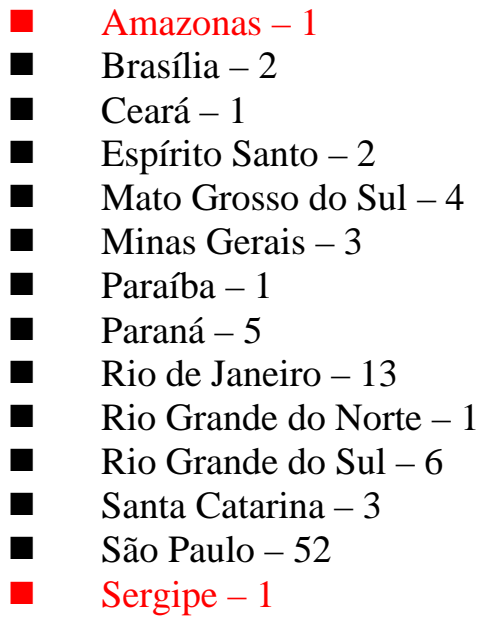

Figura 11 - Estados de origem dos autores que enviaram artigos para a RBEE (2001). 

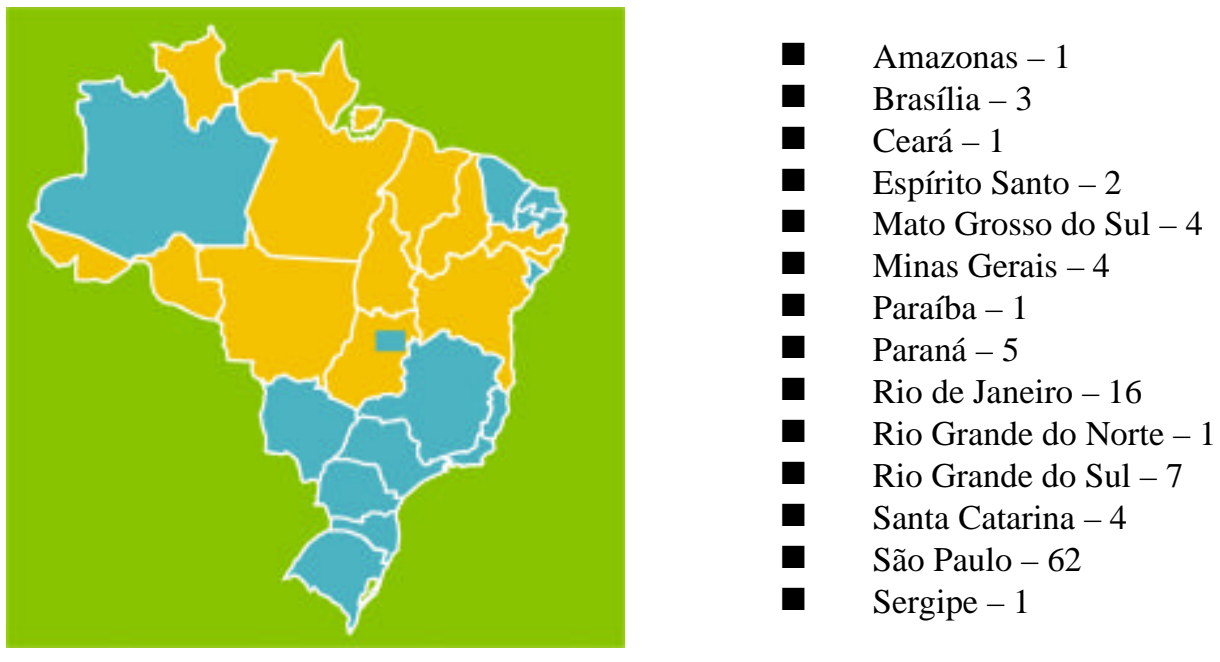

Figura 12 - Estados de origem dos autores que enviaram artigos para a RBEE (2002).
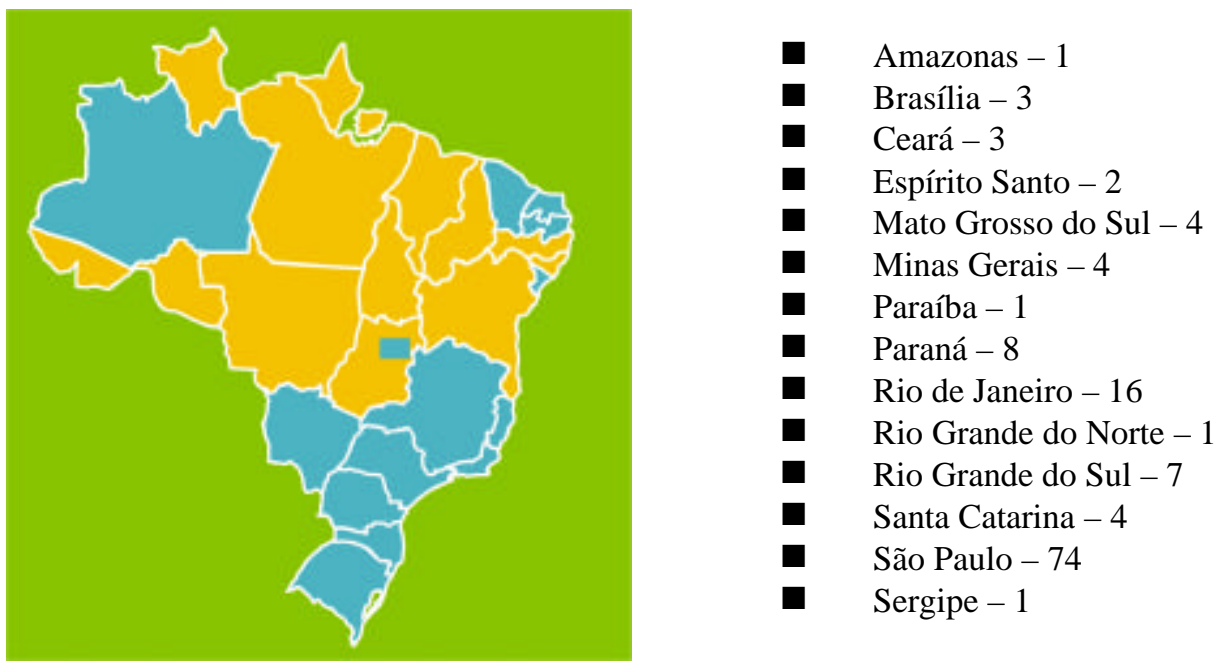

Figura 13- Estados de origem dos autores que enviaram artigos para a RBEE (2003). 

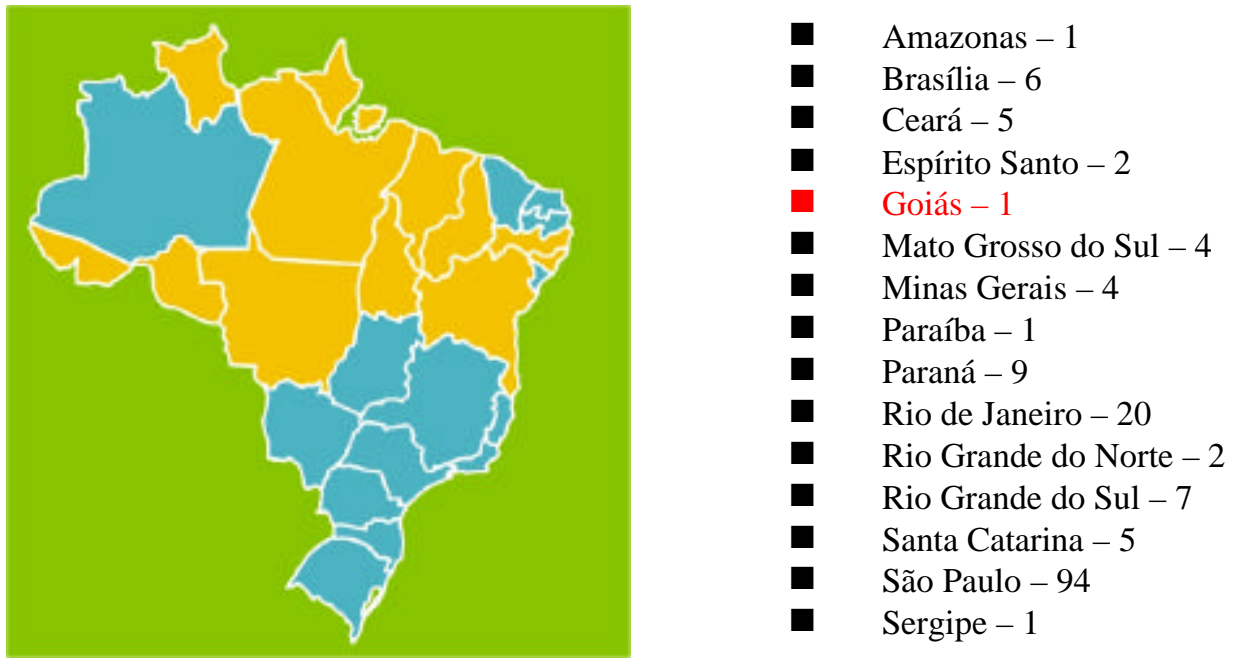

Figura 14 - Estados de origem dos autores que enviaram artigos para a RBEE (2004).

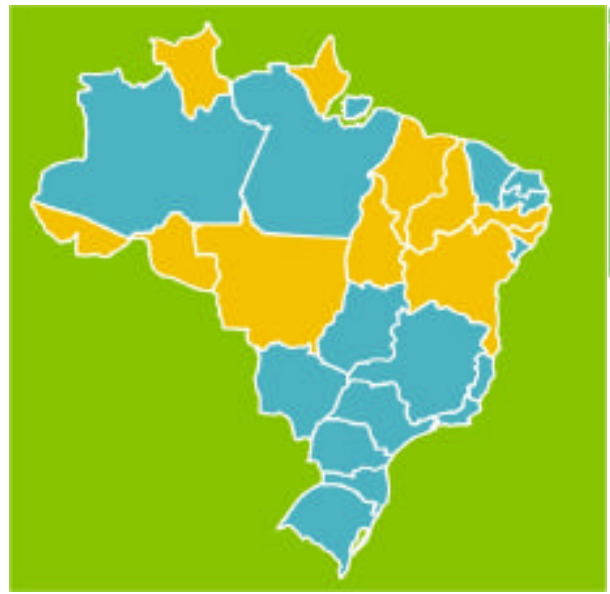

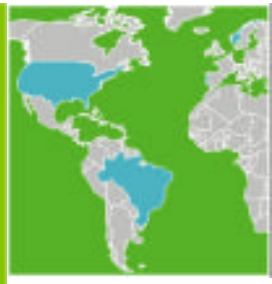

Noruega -1

USA -1

Portugal - 1

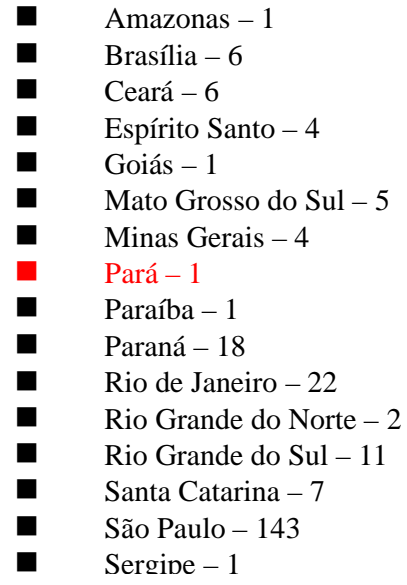

Figura 15 - Estados de origem dos autores que enviaram artigos para a RBEE (2005). 


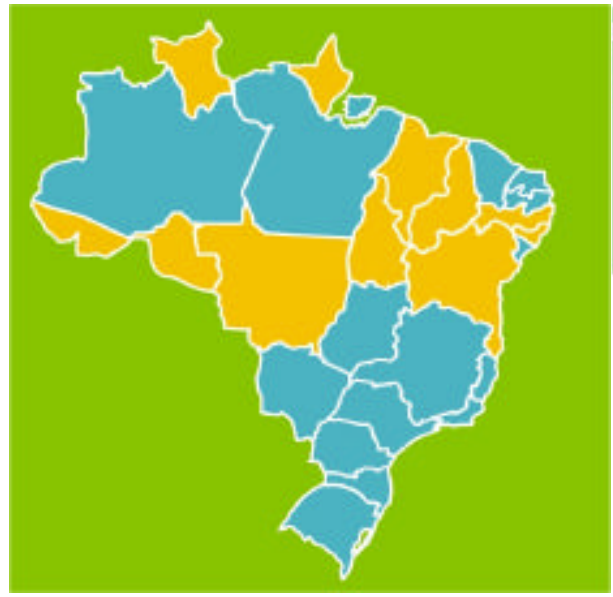

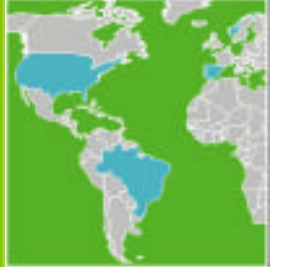

Noruega -1

USA - 1

Espanha - 1

Portugal -2
- Amazonas - 1

- Brasília - 6

- Ceará - 6

- Espírito Santo - 4

- Goiás - 1

- Mato Grosso do Sul - 5

- Minas Gerais - 4

- Pará - 1

- Paraíba - 1

- Paraná - 18

- Rio de Janeiro - 22

- Rio Grande do Norte - 2

- Rio Grande do Sul - 11

- Santa Catarina - 7

- São Paulo - 143

- Sergipe - 1

Figura 16 - Estados de origem dos autores que enviaram artigos para a RBEE (2006).
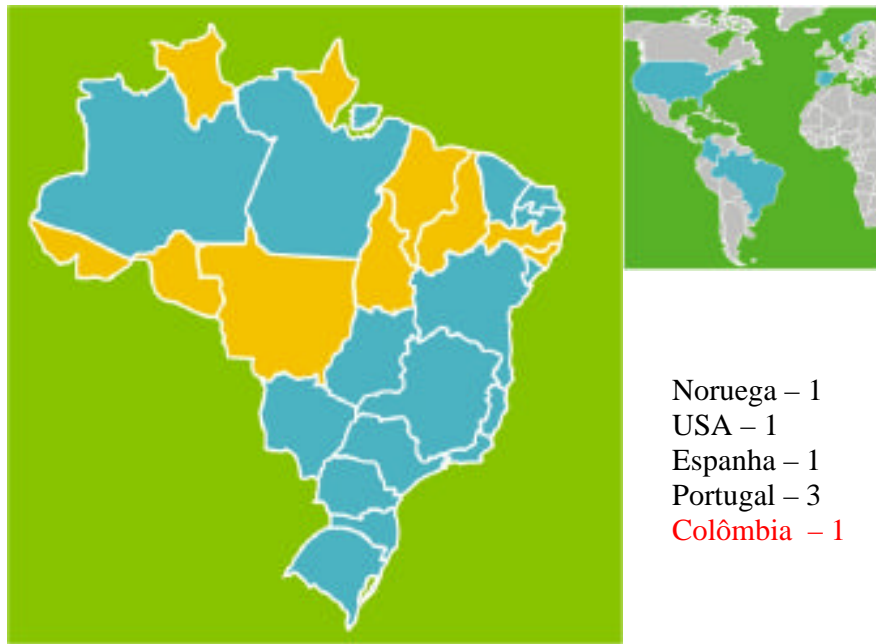

Noruega - 1

USA - 1

Espanha - 1

Portugal - 3

Colômbia -1

Figura 17 - Estados de origem dos autores que enviaram artigos para a RBEE (2007). 

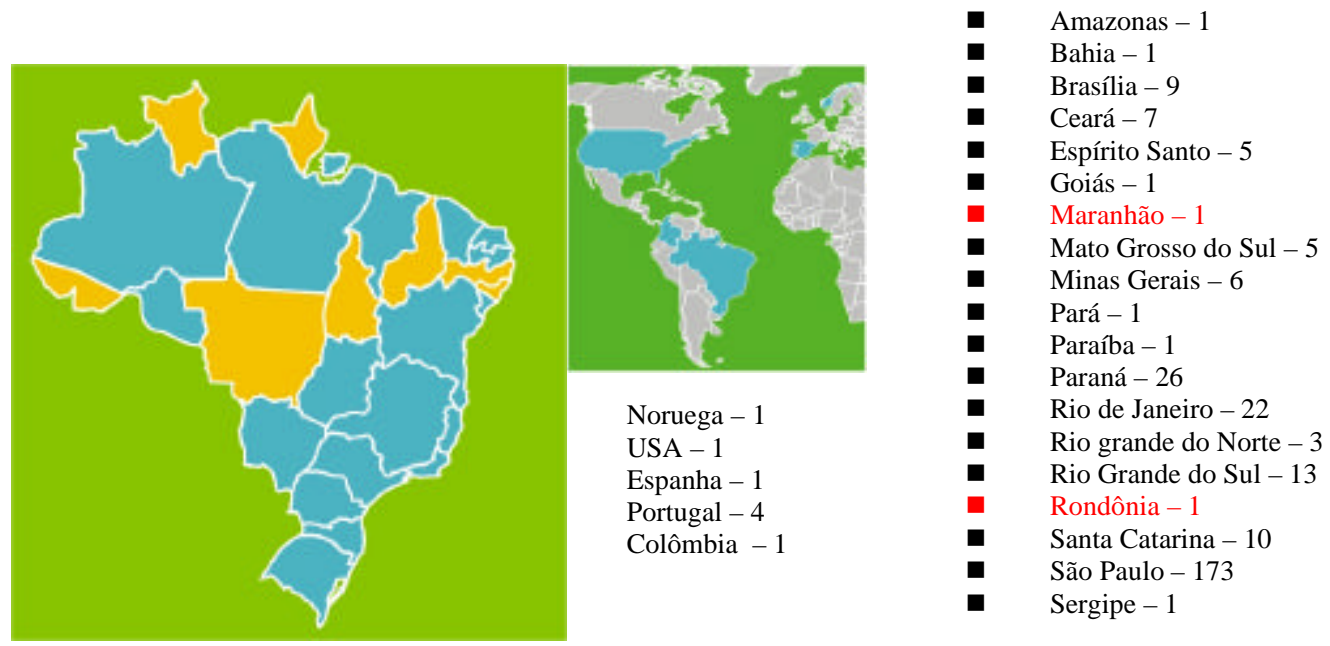

Figura 18- Estados de origem dos autores que enviaram artigos para a RBEE (2008).

Observando Figuras, é possível verificar que os artigos enviados para a RBEE foram oriundos das regiões sul e sudeste. Este quadro tem seu início entre 1992 e 1994. Em 1995, a revista começou a receber artigos da Região N ordeste e Centro-oeste e em 2000, recebeu o primeiro artigo da Região N orte.

Nota-se nos dados das Figuras anteriores que seis Estados Brasileiros ainda não entraram para o computo de artigos enviados para a RBEE. Constatase, também, que os Estados que mais publicaram artigos na Revista foram: São Paulo (173); Paraná (26) e Rio de Janeiro (22). Esse dado reforça a tese da existência de uma relação estreita entre a produção de conhecimento e a Pósgraduação, pois existe grande concentração de Programas de Pós-graduação em São Paulo, com linhas de pesquisa em Educação Especial.

Sabendo-se, então, dessa concentração, existiria uma vinculação entre a procedência dos autores que publicaram na RBEE e a procedência dos Sócios da ABPEE?

Essa pergunta é relevante, pois, com o avanço da ABPEE, pareceu necessário uma primeira dissociação entre a Revista e os objetivos da Associação, que culminou com a reformulação do estatuto em 2005 e com a indicação do cargo de editor. A pesar de o editor ser profissional que poderia ser indicado pela diretoria, ele seria parte dela.

Para responder a essa pergunta, foi feito um levantamento da procedência dos autores da revista. A Tabela 1 apresenta esses dados. 
Tabela 1 - Procedência dos autores e sócios da ABPEE e da RBEE (1992- 2008).

\begin{tabular}{|c|c|c|}
\hline Estados & $\begin{array}{c}\text { Proveniência dos } \\
\text { Autores } \\
\end{array}$ & Número de Sócios \\
\hline Acre & 0 & 0 \\
\hline Alagoas & 0 & 2 \\
\hline Amapá & 0 & 0 \\
\hline Amazonas & 1 & 3 \\
\hline Bahia & 1 & 8 \\
\hline Brasília & 9 & 7 \\
\hline Ceará & 7 & 3 \\
\hline Espírito Santo & 5 & 8 \\
\hline Goiás & 1 & 3 \\
\hline Maranhão & 1 & 3 \\
\hline Mato Grosso & 0 & 0 \\
\hline Mato Grosso do Sul & 5 & 6 \\
\hline Minas Gerais & 6 & 9 \\
\hline Pará & 1 & 3 \\
\hline Paraíba & 1 & 2 \\
\hline Paraná & 26 & 30 \\
\hline Pernambuco & 0 & 2 \\
\hline Piauí & 0 & 1 \\
\hline Rio de Janeiro & 22 & 23 \\
\hline Rio grande do Norte & 3 & 10 \\
\hline Rio Grande do Sul & 13 & 14 \\
\hline Roraima & 1 & 0 \\
\hline Rondônia & 1 & 0 \\
\hline Santa Catarina & 10 & 5 \\
\hline São Paulo & 173 & 128 \\
\hline Sergipe & 1 & 4 \\
\hline Tocantins & 0 & 0 \\
\hline
\end{tabular}

Observando a Tabela 1, percebe-se, também uma concentração de sócios da ABPEE nos três Estados que mais publicaram na Revista Brasileira de Educação Especial: São Paulo (128); Paraná (30) e Rio de Janeiro (23). 


\section{Contribuições da A BPEe para a Educação Especial}

Pelos dados apresentados, a contribuição da ABPEE para a disseminação deconhecimento éincontestável econclui-seque os objetivos iniciais da Associação foram atingidos.

Também parece ser importante frisar que, a partir de 2005, a revista começou o seu processo de internacionalização, sendo enviada para 23 países e recebendo artigos do exterior, tendo Portugal como o primeiro país da lista em número de artigos enviados.

Como a manutenção da Revista e da Associação é um processo que deve continuar com as diretorias que irão suceder as atuais, é preciso dimensionar aonde se deseja chegar. Para contribuir com esse processo, apresentam-se três perguntas que deverão ser respondidas pelos sócios da ABPEE, por seus diretores e pelo editor da Revista Brasileira de Educação Especial:

1) Qual direção se deseja imprimir para a futura contribuição da ABPEE para a Educação Especial?

2) Qual nível de abrangência nacional se deseja?

3) Qual nível de internacionalização se deseja al cançar?

Finalizando, a ABPEE também obteve o status de editora e passou a publicar livros e a solicitar ISBN e ISSN para os eventos da Educação Especial, como previa um de seus objetivos de criação. A Revista Brasileira de Educação Especial foi avaliada e classificada no Qualis A2, passando a configurar no enquadre de revista internacional. Tem conseguido financiamento do CN Pq, mas continua precisando do apoio dos Sócios da ABPEE para manter a sua circulação.

\section{Referências}

A CONSOLIDAÇÃ O DE UM PROJETO. Revista B rasileira deE ducação Especial, Piracicaba, v.3, n.1, 1995.

CA PES. A valiação da Pós-graduação. Relatório dos Programas dePós-graduação em Educação. Triênio 2004-2006. Disponível em: www.capes.gov.br. Acesso em 25/ 11/ 2008.

CAPES. A valiação da Pós-graduação. Relatório dos Programas dePós-graduação de

Psicologia. Triênio 2004-2006. Disponível em: www.capes.gov.br. A cesso em 25/ 11/ 2008. 
DIAS, T. R. S. Porque uma revista de educação especial: o início. R evista Brasileira de Educação Especial, Marília, v.9, n.1, p.1-15, 2003.

Editorial. Revista Brasileira de Educação Especial, Piracicaba, v.1, n.1, 1992.

Editorial. Revista Brasileira de E ducação Especial, Piracicaba, v.2, n.1, 1994. 